American Journal of Applied Sciences 5 (11): 1558-1561, 2008

ISSN 1546-9239

(C) 2008 Science Publications

\title{
On the Views of Carbon Tax in Korea
}

\author{
Heon-Goo Kim \\ Legislative Research Bureau, Korea National Assembly, No. 1 Yoido dong, \\ Young deung po-ku, Seoul 150-703, South Korea
}

\begin{abstract}
To comply with the UNFCCC agreement, many countries are expected to make efforts to reduce the greenhouse gas emission level down to 1990 by the year of 2012. The agreement is intended to reduce the consumption of fossil fuel that causes the greenhouse effect. The global warming has been accelerated by the greenhouse effect resulted from the $\mathrm{CO}_{2}$ emission and has become a serious global issue requiring a fundamental solution. Many environmentalists regard the carbon tax imposition on fossil fuel consumption as an efficient measure to reduce the greenhouse gas, i.e., $\mathrm{CO}_{2}$. Environmentalists and scholars in Korea are generally showing positive attitudes toward this tax scheme.
\end{abstract}

Key words: UNFCCC, greenhouse effect, $\mathrm{CO}_{2}$ emission, carbon tax

\section{INTRODUCTION}

UNFCCC (United Nations Framework Convention on Climate Change) has been agreed upon in Rio in 1992. This led to the Kyoto Protocol in 1997 by establishing a goal to reduce greenhouse gas among countries. It has been an important issue since the mid1980s. The purpose of this agreement is to reduce the consumption of fossil fuels which causes the greenhouse effects. Because of this, global warming has become a serious matter to be solved by $m$ andatory controls to use less fossil fuels. According to this agreement, the developed countries should reduce the emission of greenhouse gas from 2008 to 2012 by 5.2\% average to maintain the emission level of 1990. The greenhouse gas to be reduced in Kyoto Protocol is comprised of carbon dioxide $\left(\mathrm{CO}_{2}\right)$, methane $\left(\mathrm{CH}_{4}\right)$, nitrous oxide $\left(\mathrm{N}_{2} \mathrm{O}\right)$, hydro fluorocarbon(HFCs), sulfur fluoridation (SF6) and perfluorocarbon (PFCs).

Out of these six gases, $\mathrm{CO}_{2}$ is the most important greenhouse gas to be controlled because it is more than $80 \%$ of all of the six gas emissions in the world. The carbon tax imposition on fossil fuel usage is regarded as the most efficient scheme to reduce the greenhouse gases among many many environmentalists. This methodology is a very simplistic way to control greenhouse emission compared with others and does not incur an international conflict. Furthermore, the revenue from this tax can be used as a source of financing environmental improvements. For these reasons, carbon tax is a highly recommendable.

Carbon tax is an excise tax which is levied according to the quantity of carbon dioxide in energy source, while energy tax is also an excise tax levied according to the energy content in energy source. In general, carbon tax is one of the environmental taxes along with energy tax. The carbon tax, however, is believed to yield a substitution effect because it brings a negative incentive in using energy source containing carbon dioxide.

In the early 1990s, the northern European countries, Denmark, Norway, Sweden and Finl and decreased the tax rates including personal income tax while they introduced or exp anded environment related taxes to compensate the reduced tax revenue. These countries have something in common to pursue a plan to initiate a carbon tax system as a tax reform. The carbon tax is now being implemented in Denmark, Finl and, Italy, Norway, Netherl ands and Sweden.

\section{THE CHARACTERISTICS OF CARBON TAX and ITS IMPLEMENTATION DEBATE}

Characteristics: The carbon tax is considered to be an indirect tax imposed on the use of fossil energy source, which is different from the direct imposition on the $\mathrm{CO}_{2}$ emission $^{[1]}$. Yoo $^{[2]}$ categorized the energy tax into two aspects, a production tax and an excise tax. The excise tax is imposed indirectly on the energy consumed in non energy sectors as the final energy. The excise tax as 
a scheme to be levied on the consumption of the final energy is a means of reducing the use of petroleum and coals.

$\mathrm{Cho}^{[3]}$ interprets the carbon tax as an environmental tax leading to decreases in contamination and waste. and it is as an efficient policy to change the production quality and induce the environmental protection. This policy leads to not only technological improvement but also energy efficient production process. As an energy tax, it induces the polluting producers to switch to the production of environmentally less harmful commodities. Thus, this tax is to give the producers opportunities to develop less harmful substitutes and make the production process less dependent on fossil fuel.

As a source of the investment on environment and a means of pollution restriction, the introduction of the carbon tax is actively debated in Korea. Seol ${ }^{[4]}$ introduces contents from Welfare Economics written by Pigou that the tax levy on the polluting materials to protect environment is justifiable.

Debate: The initial international debate on environment tax including carbon tax began with OECD's evaluation of various tax schemes concerned with excise tax, value added tax and automobile related taxes. During this process, four countries (Norway, Netherl ands, Sweden and Finl and) focused mainly on carbon tax. In Korea, there is no environment related tax law as a national tax law but only a transportation tax related to air pollution as a local tax. To reduce the air pollution, people think the best way is to levy the tax according to the emission quantity if it can be measurable. This method, however, is unable to measure accurately and requires a lot of cost related to administration and information. Thus, the simple method is to levy the tax on the fuel containing pollution material, which can satisfy the PPP(Polluter Pays Principle). This method is represented as a carbon tax law which should be introduced in Korea.

In Korea, $\mathrm{Kim}^{[5]}$ argues for indirect tax scheme rather than direct method on the basis of PPP(Polluter Pays Principle) to internalize the external cost caused by $\mathrm{CO}_{2}$ emission. Shin ${ }^{[6]}$ also agrees with the introduction of carbon tax to reduce the $\mathrm{CO}_{2}$ emission efficiently, in spite of the debates such as JI(Joint Implementation), $\mathrm{CDM}(\mathrm{Clean} \quad$ Development Mechanism) and IET(Internal Emission Trading).

Even if our country's production structure has a lower substitutability of other inputs for energy input, the substitutability will increase in the long run. The carbon tax system will stimulate the substitution effect, which will transform our economic structure through energy saving production technology ${ }^{[7]}$.

Choi ${ }^{[8]}$ asserts that the lower the carbon tax rate is, the lower the price change effect will be. At the high carbon tax rate, the big fluctuation in price changes by industry occurs. This will yield a large tax revenue to the government. He suggests to apply a dem and management policy to carbon tax in the industries having big price changes.

$\operatorname{Shin}^{[9]}$ maintains that the Korean policy in response to UNFCCC should be to reduce the greenhouse gas through the development of energy efficient technology. This policy will be effective when it is implemented with market oriented strategies under carbon tax system.

\section{EXPECTED ECONOMIC EFFECT FROM CARBON TAX}

Chung and Rhe ${ }^{[10]}$ expect that the carbon tax will increase the energy price which will affect the change in production cost structure. The increase in production cost will increase in prices of commodities of relatively energy intensive using industries, which will change the whole economic structure. This change in domestic prices will ultimately decrease the country's competitiveness in the international market. The price increase due to the implementation of carbon tax is from our country's price-inelastic energy dem and. In other words, there is a low substitutability of fossil fuel input for another kind of input emitting less $\mathrm{CO}_{2}$.

The far reaching effect from the energy price increase induces burdens to the industries using fossil fuel as raw materials and intermediate inputs. Especially the sectors such as primary metal products, cement, warehouse, chemical products and petroleum products are showing a disbenefit, cost increase relatively to other sectors using less fossil fuel input. These sectors having disbenefit, however, will also affect negatively other sectors through overall price increases in the end.

In case of adoption of carbon tax in the developed countries, our country's export to those countries will be negatively affected. The developed countries will set up a st andard level of energy efficiency in the production process. These st andards as a non-tariff barrier will be asked to other countries which want to export to those developed countries. ${ }^{[1]]}$ The developed 
countries' introduction of it is also expected to accompany the tariff on the product from the countries which do not introduce it. This will hamper the price competitiveness of our commodities in the market of those countries.

The sectors or countries that are less affected by carbon tax can be benefited. For example, the R and D to develop the technology for the avoidance of carbon tax can create an excessive benefit to other producers and sectors. This benefit also transfers to the producers in the developing countries who want to reduce cost by accessing to the technology less harmful to the environment $^{[12]}$.

About the matter of introduction of carbon tax, Cho explains negative or positive aspects that may arise. The negative opinion is of the possibility of transferring the carbon tax burden from producers to consumers. This happens when the dem and for the product is price inelastic as price increases. This price increase implies that a part of the environmental tax burden to producers is transferred to the consumers who cannot find a substitute product. The dem and decrease due to the price increase may lead to production decrease that may yield wage decrease and unemployment.

The positive aspect is the possibility of enhancing the competitiveness of firms or industries caused by investing in research and development projects. The production process innovation leading to increasing return to scale may disconnect the negative tie between economic growth and environment. The innovation for clean products and production facilities may accompany the environmental protection with firms' competitiveness enhancement. As a result, the environmental regulations may lead to innovation more than the offsetting level of cost increase. In the long run, the initial impact on the energy price increase can be an economic benefit. For this, Cho (2004) makes an example of Italy's increasing export share of small vehicles equipped with technology developed in response to high tax on fossil fuel.

\section{THE WORLD ATTITUDE TOWARD CARBON TAX}

The carbon tax system is the outcome of finding a measure positively to resolve the environmental problems without being controlled under the environmental policy system of the past. This system is believed to be convenient to levy, increase the tax revenue and reduce the omission of $\mathrm{CO}_{2}$. This system is effective in about 6 European countries, but other EU countries and the United States are in a full deliberation of introducing this system. The United States is the country emitting $20 \%$ of the total $\mathrm{CO}_{2}$ emission throughout the world.

In spite of their underst anding the necessity of introducing the carbon tax system, there are some reasons in hesitating the implementation of the system. First, they worry about the bad effect on the national economy such as GDP decrease and unemployment after the implementation of it. Second, they assert that the global warming is the problem of the world instead of confining to a certain region. This problem should be solved with JI (Joint Implementation) after setting up a system for an international cooperation.

Amidst these negative and pessimistic attitudes toward the carbon tax, we can see the optimistic forecasts and positive results from implementing $\mathrm{it}^{[4]}$.

- Denmark implemented the carbon tax system in 1995 and expected $3.8 \%$ of $\mathrm{CO}_{2}$ emission would be reduced in 2005

- The study by a Swedish environmental bureau showed the quantity of $\mathrm{CO}_{2}$ emitted in 1994 was 8 million tons which was lower level than that of 1987. They analyzed this reduction of $\mathrm{CO}_{2}$ emission was from the carbon tax, which leaded to a great effect in a short period of time

- Norway introduced the carbon tax in 1991 and estimated the emission of $\mathrm{CO}_{2}$ by $21 \%$ in stationary power plants in 1995. The oil that Norwegian petroleum sector produced was estimated to reduce the emission of $\mathrm{CO}_{2}$ by $1.5 \%$ in response to carbon tax system

- In 1999, the Finnish economic committee evaluated the effectiveness of carbon tax. That report estimated the $\mathrm{CO}_{2}$ emission by assuming no increase in carbon tax of the year 1990 level and concluded there would be an emission of $7 \%$ increase in $\mathrm{CO}_{2}$ in 1998. This report estimated that the reduction in consumption of fossil fuel and production structural change in industry resulted in the reduction of emission by one million tons of $\mathrm{CO}_{2}$ emission. The reduction of $2 / 3$ of the emission was estimated from the substitution of natural gas for petroleum and coal

\section{CONCLUDING REMARKS}

A study by Kim and $\operatorname{Shin}^{[13]}$ analyzed that Korea depends on petroleum and coal products in producing commodities more than China, Japan and the US in response to the carbon tax system. By introduction of carbon tax, Korea will be the 
worst victim compared with our main trading countries. The developed countries such as the US and Japan have less vulnerability to the carbon tax than Korea. Despite their less vulnerability, they have reached at the advanced stage of development of hi-tech energy source in order to lessen the dependability on fossil fuel.

The general attitude toward the carbon tax in Korea is rather positive among the environment related scholars and specialists. Many Koreans think they have experienced the dependency on fossil fuel using production technologies the developed countries developed. In order to divorce from the fossil energy using system, most of them think it's necessary to develop their own energy efficient production structure. This will not make Korea repeat the possible subordination to energy saving technology the developed countries would develop in the future to come.

These people do not concern about the GDP decrease and unemployment followed by the carbon tax implementation as the people in the developed countries. The bad effect on the national economy will be at the initial stage, but this will make our economic structure improved. The effort to reduce the emission of $\mathrm{CO}_{2}$ in accordance with UNFCCC will enhance the air quality and stimulate the development of technology. Ultimately, the energy efficient industrial production structure will be established with a sustainable growth.

It is highly recommended that we must focus on energy saving and efficiency especially in the energy intensive using industries. This is the way to compensate for the worsening their competitiveness due to carbon tax implementation in the international arena. The policy for energy saving and efficiency should be based on the provision of incentives to entice the firms' participation. For this, there should be recommendations to the firms with appropriate production facilities for energy saving and efficiency according to the firms' size and business.

\section{REFERENCES}

1. Choi, S. and J. Hong, 2000. General Equilibrium Analysis on the Economic Effects of Greenhouse Gas Emission Control in Korea. Korean J. Publ. Finance, 15 (1): 223-240.
2. Yoo, S.H., 1994. Impacts of Carbon Tax on Industries. Environ. Econ. Rev., 4 (1): 41-65.

3. Cho, Y., 2005, Environmental Strategy of OECD Members. J. Econ. Manage., 5 (1): 153-191.

4. Seol, K.K., 2006. A Study on the Introduction of Environmental Tax. Hankook Universtiy of Foreign Studies Law Review, 22: 297-321.

5. Kim, S., H., 1997, A Study on the Effect of Carbon Taxes on the Industrial Sector in Korea. J. Regional Dev., 3: 263-284.

6. Shin, D.C., 2000. Scale Economies and the Effects of a Carbon Tax on Korean Economy: A CournotWalrasian CGE Simulation. Environ. Resour. Econ. Rev., 9 (5): 973-997.

7. Park, J.S., 2003. An Economic Approach to Climate Change Policy, J. Social Sci., 20 (2): 233-259.

8. Choi, Y.H., W.Y. Lim and S.H. Kim, 2000. The Price Variable Effect of Carbon Tax per Industry. Q. Rev. Econ. Business, 28 (1): 1-17.

9. Shin, E.S. and H. Kim, 2003. Analysis of the Impacts of Carbon and Energy Taxes on Energy on Energy System in Korea. Environ. Resour. Econ. Rev., 12 (2): 275-298.

10. Chung, H.S. and H.C. Rhee, 1995. Changes in Price Structure of Korean Industries from Carbon Tax Imposition. Environ. Econ. Rev., 4 (1): 113-150.

11. Lee, J.W., C.S. Park and H. Kang, 1994. How the Imposition of Carbon Tax Will Affect the Korean Export to EU? (With Special Reference to the Primary Nonferrous Metals and Motor Vehicles Industry). Korean Econ. Rev., 21 (1): 231-263.

12. Kim, H.B. and W.H. Yoo, 2002. Impact Analysis of Carbon dioxide Reduction Policy in a Regional Economy by Multi-regional input-output Model. J. Korea Plann., 37 (7): 195-206.

13. Kim, H.G. and H.J. Shin, 2007. An Analysis of Changes in Production and Trade of US, Japan, China and Korea Affected by Levy of Carbon Tax. Int. Area Stud. Rev., 11 (1): 273-291. 